\title{
Malaria Characteristics in Children with Sickle Cell Disease
}

\author{
Indou Deme/Ly1, Cheikh Binetou Fall1, Awa Kane1, Ibrahima Diop1, Aminata Mbaye1, \\ Yaaye Joor Dieng', Denika Estelle Liapoui ${ }^{1}$, Idrissa Demba Ba ${ }^{1}$, Abou Ba ${ }^{1}$, Aliou Thiongane ${ }^{1}$, \\ Papa Moctar Faye ${ }^{1}$, Amadou Lamine Fall ${ }^{1}$, Ibrahima Diagne ${ }^{2}$, Ousmane Ndiaye ${ }^{1}$
}

${ }^{1}$ Cheikh Anta Diop University, Dakar, Senegal

${ }^{2}$ Gaston Berger University, Saint-Louis, Senegal

Email: indou.deme@ucad.edu.sn

How to cite this paper: Deme/Ly, I., Fall, C.B., Kane, A., Diop, I., Mbaye, A., Dieng, Y.J., Liapoui, D.E., Ba, I.D., Ba, A., Thiongane, A., Faye, P.M., Fall, A.L., Diagne, I. and Ndiaye, O. (2022) Malaria Characteristics in Children with Sickle Cell Disease. Open Journal of Pediatrics, 12, 125-130. https://doi.org/10.4236/ojped.2022.121013

Received: January 8, 2022

Accepted: February 22, 2022

Published: February 25, 2022

Copyright $\odot 2022$ by author(s) and Scientific Research Publishing Inc. This work is licensed under the Creative Commons Attribution International License (CC BY 4.0).

http://creativecommons.org/licenses/by/4.0/ (c) (i) Open Access

\begin{abstract}
Background: The relationship between sickle cell disease and malaria is the subject of much controversy. However, there is a lack of data in our services. Our objective was to study the epidemiological, diagnostic and evolutionary characteristics of malaria in children with sickle cell disease followed in a specialized setting. Patients and Methods: We conducted a retrospective, descriptive, and analytical study of children with sickle cell disease (SCD) who presented with malaria and were followed at the Ambulatory Care Unit for Sickle Cell Children and Adolescents (USAD) at the Albert Royer National Children's Hospital in Dakar, from January $1^{\text {st }}, 2017$, to December $31^{\text {th }}, 2019$. We included all the followed pediatric patients, less than 16 years, with sickle cell disease who presented at least one episode of malaria, confirmed by a positive thick drop, during this 3 years. We did not include patients with incomplete records or those older than 16 years. The clinical and biological signs, the follow up was collected and analyzed with Excel package 2019. Results: Of 3773 patients followed for sickle cell disease, 21 had presented malaria. The frequency was $0.5 \%$ or 7 cases/year. However, we exploited the data of 14 of them. The sex ratio was 6 boys for a girl and the mean age at admission was 7.3 years. The highest number of malaria cases was observed in 2018 and the peak frequency was observed in November with 8 cases $(57.1 \%)$. Fever was the most frequent symptom, observed in 10 patients (71.4\%). All patients were SS homozygous, with a mean baseline hemoglobin level of $7.5 \mathrm{~g} / \mathrm{dl}$. All patients had a positive thick blood smear and Plasmodium falciparum was the only species found in the blood smear, with a mean parasite density of 1693 parasites $/ \mathrm{ml}$ of blood. All patients had anemia, with a mean hemoglobin level of $7.74 \mathrm{~g} / \mathrm{dl}$. Twelve patients (85.7\%) were hospitalized and had all received injectable artesunate followed by oral Artemisinin Combination Therapy (ACT). Long-lasting insecticidal nets were used in 9 patients (69.2\%). The evolution was
\end{abstract}


favorable in all patients, any death was reported. NO REPRESENTATION OF YOUR DATA IN TABLES OR FIGURES: it was a little serial. Conclusion: The patients who presented the association of malaria and sickle cell disease were all SS homozygotes. However, malaria must be considered as serious in this chronic anemic setting. That's why it is important to improve prophylaxis.

\section{Keywords}

Malaria, Sickle Cell Disease, Children

\section{Introduction}

Malaria is a major public health problem in our countries where its distribution is similar with sickle cell disease. The association of these 2 diseases is responsible of an important morbi-mortality. Many theories have been evoked about the relationship between these two diseases [1]. In our countries we do not have many data about malaria and sickle cell in children. It is in this context that we carried out this retrospective, descriptive and analytical study. Our aim was to study the epidemiological, diagnostic and evolutionary characteristics of malaria in sickle cell patients followed in a specialized setting.

\section{Patients and Methods}

We conducted a retrospective, descriptive, and analytical study of children with sickle cell disease (SCD) followed at the Ambulatory Care Unit for Sickle Cell Children and Adolescents (USAD) at the Albert Royer National Children's Hospital in Dakar, from January $1^{\text {st }}, 2017$, to December $31^{\text {th }}, 2019$. We included patients who presented at least one episode of malaria, confirmed by a positive thick drop, during the 3 years of the study. We did not include patients with incomplete records or those older than 16 years. For quantitative data, average and percentage were calculated and analyzed with Excel package 2019.

\section{Results}

Out of an active file of 3773 patients followed up for sickle cell disease, 21 had presented malaria, representing a hospital frequency of $0.5 \%$ or 7 cases/year. However, the data were exploited for 14 of them. The sex ratio was 6 and the mean age was 7.3 years. Children over 5 years of age represented $64.3 \%$ of the study population and the majority were from the urban area of Dakar (64.3\%). The highest number of malaria cases was observed in 2018 and the peak frequency was observed in November with 8 cases (57.1\%). Fever was the most frequent symptom, observed in 10 patients (71.4\%). All patients were SS homozygous, with a mean baseline hemoglobin level of $7.5 \mathrm{~g} / \mathrm{dl}$. The Rapid Diagnostic Test (RDT) was positive in 13 patients (92.8\%) and the Thick Film Test was positive in all patients. Plasmodium falciparum was the only species found in the 
blood smear. The average parasite density was 1693 parasites $/ \mathrm{ml}$ of blood. All patients had anemia, with a mean hemoglobin level of $7.74 \mathrm{~g} / \mathrm{dl}$ at the time of the malaria episode. Thrombocytosis was observed in 10 patients and positive CRP in $7 / 11$ patients $(63.6 \%)$. Twelve patients $(85.7 \%)$ were hospitalized with a mean duration of 7.4 days. Bone vaso-occlusive crisis was the main associated manifestation. No clinical signs of malaria severity were found, according to WHO criteria, 2015. All patients had received injectable artesunate with a mean duration of 3.2 days, then Artemisinin-based Combination Therapy (ACT) were prescribed as oral relay. Two patients were followed as outpatients on ACT. Eight (8) patients were transfused with iso-group and iso-rhesus red blood cells. Nine (9) patients (69.2\%) used Long Lasting Insecticidal Nets for prophylaxis. All patients had a favorable outcome.

We used insecticide only for prophylaxis.

We identified the parasite SPP and density with the SMear.

\section{Discussion}

Malaria and sickle cell disease are a public health problem in the same geographical area distribution. Over 4 years, we found 21 cases, or 7 cases per year, all was SS homozygotes. In 1999, Diagne et al. found 30 cases in the same cohort, over a period of 7 years, corresponding to 4 cases per year [2]. This increase in the number of cases from 4 to 7 per year could be explained by the increase in the size of the cohort and the active file, as well as the availability of rapid diagnostic tests for malaria and better training of human resources. In Senegal, an overall decrease in the incidence of malaria is observed, thanks to the National Malaria Control Program (PNLP). In the Democratic Republic of Congo (DRC), Aloni et al. found 90 cases of malaria in SS homozygous sickle cell disease over 10 years [3]. [As a reminder, the DRC is located in the equatorial zone and Senegal in the Sudano-Sahelian zone.]

What has this got to do with discussion? Malaria distribution depends on the type of the climate. These 2 regions have different bioclimatic conditions which influence the level of malaria transmission which is higher in the equatorial zone.] With 6 times more boys than girls, our results were comparable to those of Aloni et al. in DRC and Ngo Linwa et al. in Cameroon [3] [4]. The age group over 5 years was the most frequent in our study, contrary to the results of Aloni et al. and Ngo Linwa and al who found that children under 5 years were the most affected [3] [4]. The peak of hospitalization in November could be explained by the humid heat of the end of the winter season with the stagnation of rainwater. These conditions are favorable for the proliferation of malaria vectors. Fever was the main clinical sign of malaria [3] [5]. We found no clinical signs of malaria severity according to the 2015 World Health Organization (WHO) clinical criteria. Komba reported conditions consistent with the WHO malaria severity criteria [6]. Plasmodium falciparum was the predominant parasite species [1] [5]. One patient had a hyperparasitemia of 13,870 parasites $/ \mathrm{ml}$. The rarity of 
severe malaria in children with sickle cell disease could be explained by the protective effect of the sickle cell gene mutation, which creates a hostile environment for parasite growth due to hypoxia in sickle cell red blood cells [1] [4]. According to some authors, $\mathrm{HbS}$ carriers are relatively protected against all forms of clinical malaria [7]. The main mechanism could probably be related to a premature elimination of malaria-infected red blood cells in vivo in the spleen [8]. Indeed, the "Malaria Hypothesis" (Haldane, 1949) is in favor of a selective advantage of AS heterozygous subjects towards malaria [9]. However, the difference in tolerance observed in some patients remains poorly elucidated. The homozygous SS genotype was the only one found in our study and in that of Aloni et al. [3]. Diagne and al. found a double heterozygote SC in the 30 patients of the 1999 series [2]. Vaso-occlusive crisis was the most frequent associated clinical manifestation [5] [6]. Anemia was normocytic in 9 patients (64.28\%) and microcytic in 5 patients $(35.71 \%)$. No thrombocytopenia was reported and 10 patients $(71.43 \%)$ had thrombocytosis. These results were comparable to the literature [4] [6] [10]. The mean hemoglobin level at the time of malaria was comparable to the mean baseline hemoglobin level. However, Warley et al. found a decrease in baseline hemoglobin level of up to $2 \mathrm{~g} / \mathrm{dl}$ in cases of malaria in sickle cell disease [11]. This difference would be related to a better tolerance of the Senegal haplotype [12]. The positive CRP in 7 patients (63.6\%) would be related to the inflammatory phenomena during malaria but also to the associated CVO. The evolution was favorable with a cure of malaria in all patients, as reported by Aloni and al [3]. The mortality was $20.4 \%$ according to Ngo Linwa and al [4]. Currently, arthemisinin derivatives contribute to reduce hospitalization time and mortality risk. The means of prevention used in our study were LLINs and the combination of sulfadoxine + pyrimethamine. This prevention is important in these patients [13]. According to Diagne and al., taking monthly sulfadoxine + pyrimethamine during the transmission period would reduce the prevalence of malaria and the need for blood transfusions in these patients [14].

In Kenya, a population-based study showed that malaria was not more frequent in children with sickle cell disease, however, mortality was about 10 times higher compared to controls without sickle cell disease [15].

Poorly written discussion: we have not many articles about malaria and sickle cell in children.

\section{Conclusion}

The patients in our study were mostly boys over 5 years of age, all SS homozygotes. Fever was the main sign of malaria and CVO was the main manifestation of sickle cell disease. The course was favorable in all patients. However, malaria must be considered as severe in this chronic anemic setting. That's why it is important to improve prophylaxis. However, the small sample size should make us think about a future case control study with a larger number of patients. What is the full meaning of CVO: vaso occlusive crisis (VOC). 


\section{Conflicts of Interest}

The author declares no conflicts of interest regarding the publication of this paper.

\section{References}

[1] Sangare, A., Sanogo, I., Ebongo, E., Meite, M., Faget, P.K., Sawadogo, S., et al. (1990) Contribution à l'étude des relations entre la drépanocytose et le paludisme. Medecine d Afrique Noire, 37, 268-273.

[2] Diagne, I., Ndiaye, O., Moreira, C., Sy, H.S., Camara, B., Diouf, S., et al. (2000) Les syndromes drépanocytaires majeurs en pédiatrie à Dakar (Sénégal). Archives of Pediatrics, 7, 16-24. https://doi.org/10.1016/S0929-693X(00)88912-5

[3] Aloni, N.M., Tshimanga, B.K., Ekulu, P.M., Ehungu, J.L. and Ngiyulu, R.M. (2013) Malaria, Clinical Features and Acute Crisis in Children with Sickle Cell Disease in Resource-Constrained Countries: Retrospective Description of 90 Cases. Pathogens and Global Health, 107, 198-201. https://doi.org/10.1179/2047773213Y.0000000089

[4] Ngo Linwa, E., Cumber, S.N., Eposse, E.C., Esuh, E.L., Mandeng, M.L., Nkfusai, C.N., et al. (2020) Malaria in Patients with Sickle Cell Anaemia: Burden, Risk Factors and Outcome at the Laquintinie Hospital, Cameroon. BMC Infectious Diseases, 20, Article No. 40. https://doi.org/10.1186/s12879-019-4757-x

[5] Diop, S., Soudre, F., Seck, M., Guèye, Y.B., Dieye, T.N., Fall, A.O., et al. (2011) Sickle-Cell Disease and Malaria: Evaluation of Seasonal Intermittent Preventive Treatment with Sulfadoxine-Pyrimethamine in Senegalese Patients-A Randomized Placebo-Controlled Trial. Annals of Hematology, 90, 23-27. https://doi.org/10.1007/s00277-010-1040-z

[6] Komba, A.N., Makani, J., Sadarangani, M., Ajala-Agbo, T., Berkley, A.J., Charles, R.J., et al. (2009) Malaria as a Cause of Morbidity and Mortality in Children with Homozygous Sickle Cell Disease on the Coast of Kenya. Clinical Infectious Diseases, 49, 216-222. https://doi.org/10.1086/599834

[7] Williams, T.N., Mwangi, T.W., Wambua, S., Alexander, N.D., Kortok, M., Snow, R.W., et al. (2005) Sickle Cell Trait and the Risk of Plasmodium falciparum Malaria and Other Childhood Diseases. The Journal of Infectious Diseases, 192, 178-186. https://doi.org/10.1086/430744

[8] Pasvol, G., Weatherall, D.J. and Wilson, R.J. (1978) Cellular Mechanism for the Protective Effect of Haemoglobin S against P. falciparum Malaria. Nature, 274, 701703. https://doi.org/10.1038/274701a0

[9] Haldane, J.B. (1949) The Rate of Mutation of Human Genes. Proceedings 8th International Congress on Genetics and Bered, Vol. 35, 267-273. https://doi.org/10.1111/j.1601-5223.1949.tb03339.x

[10] Makani, J., Komba, A.N., Cox, S.E., Oruo, J., Mwamtemi, K., Kitundu, J., et al. (2020) Malaria in Patients with Sickle Cell Anemia: Burden, Risk Factors, and Outcome at the Outpatient Clinic and during Hospitalization. BMC Infectious Diseases, 20, Article No. 40.

[11] Warley, M.A., Hamilton, P.J., Marsden, P.D., Brown, R.E., Merselis, J.G. and Wilks, N. (1965) Chemoprophylaxis of Homozygous Sicklers with Antimalarials and LongActing Penicillin. British Medical Journal, 2, 86. https://doi.org/10.1136/bmj.2.5453.86

[12] Powars, D.R. (1991) Sickle Cell Anemia: Beta s-Gene-Cluster Haplotypes as Pronostic Indicators of Vital Organ Failure. Seminars in Hematology, 28, 202-208. 
[13] Oniyangi, O. and Omari, A.A. (2006) Malaria Chemoprophylaxis in Sickle Cell Disease. Cochrane Database of Systematic Reviews, No. 4, CD003489.

https://doi.org/10.1002/14651858.CD003489.pub2

[14] Diagne, I., Gueye, N.D., Sy, H.S., Camara, B., Sall, P.L., Sarr, M., et al. (2003) Prise en charge de la drépanocytose chez l'enfant en Afrique: Experience de la cohorte de l'hôpital d'enfants Albert Royer de Dakar. Medecine Tropicale, 63, 513-520.

[15] Luzzatto, L. (2012) Sickle Cell Anaemia and Malaria. Mediterranean Journal of Hematology and Infectious Diseases, 4, e2012065.

https://doi.org/10.4084/mjhid.2012.065 